\title{
INFLUENCE OF LASER ENERGY IN THE SURFACE QUALITY OF Parts Manufactured by Selective LaSer Melting
}

\author{
Pablo Zapico, Sara Giganto, Susana Martínez-Pellitero, \\ Ana Isabel Fernández-Abia \& $\mathrm{M}^{\mathrm{a}}$ Ángeles Castro-Sastre
}
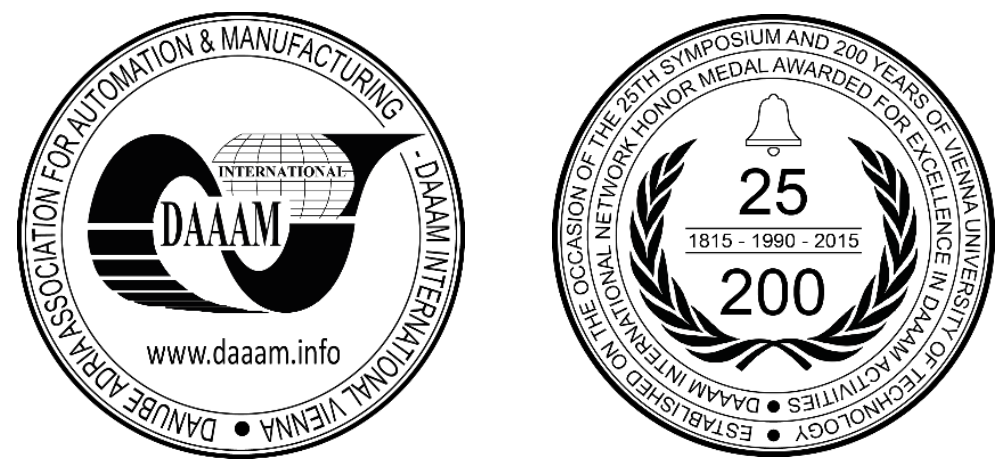

This Publication has to be referred as: Zapico, P[ablo]; Giganto, S[ara]; Martinez Pellitero, S[usana]; Fernandez - Abia, A[na] I[sabel] \& Castro Sastre, M[aria] A[ngeles] (2018). Influence of Laser Energy in the Surface Quality of Parts Manufactured by Selective Laser Melting, Proceedings of the 29th DAAAM International Symposium, pp.0279-0286, B. Katalinic (Ed.), Published by DAAAM International, ISBN 978-3-902734-20-4, ISSN 1726-9679, Vienna, Austria DOI: $10.2507 / 29$ th.daaam.proceedings.040

\begin{abstract}
Selective Laser Melting (SLM) is an important additive manufacturing technique of great interest to the Aerospace and Automotive industries because of the possibility to obtain high complex parts with material savings, in contrast to conventional processes. In SLM, parts are built layer by layer using a high power-density laser which is capable to selectively melt a powder layer bed and joined it with the previously melted one. Despite the high advantages of this technique for the cited industries, the tight quality requirements in their parts together with the lack of characterization of properties of parts obtained by SLM technique limit its real application. In this work, the influence of the quantity of laser energy absorbed by the 17-4PH stainless steel powder during the SLM process on the surface quality obtained is analysed. For this, the influence of laser power parameter of the ProX 100 SLM machine was studied. Also, the influence of defocussing parameter was studied because of its effect in the laser energy concentration on the powder bed. To characterize the influence of the cited parameters in the surface quality of the parts, a Jeol JSM-6480LV scanning electron microscope (SEM) and a SJ-500P contact profilometer were used.
\end{abstract}

Keywords: additive manufacturing; SLM technique; surface quality; 17-4PH stainless steel

\section{Introduction}

The fact that Additive Manufacturing possibilities to manufacture complex geometry parts, facilitates its expansion to different industrial sectors. Every day new techniques to produce complex parts with different materials, from polymers to metals arise. One of the most interesting technologies in sectors such as Aeronautics or the Automobile, is the Selective Laser Melting (SLM), Fig. 1a, belong to so called laser powder bed fusion (LPBF) or powder bed laser fabrication process. From 3D CAD data, parts are built layer by layer using a high power-density laser which is capable to selectively melt a powder layer bed and joined it with the previously melted one. The main advantages of SLM are the wide range of possible geometries and light weight structures. Ni-based superalloys, Fe-alloys, and Ti-alloys are commonly used SLM powder materials. 
However, although SLM is a promising technique, there are still problems with regard to the quality of parts: poor surface quality and the need of secondary processes to improve it [1], or presence of porosity, which negatively affects the parts properties [2]. In general, these aspects depend and are mainly determined by the interactions between parameters of the SLM process. After the review carried out, among the most studied parameters are: hatch distance, layer thickness, scanning velocity, laser power or defocussing [3], [4], [5]. It was concluded that these, the only ones to be set specifically for each machine are power and defocussing, since the other parameters are manufacturer recommended values and belonging to its own know-how.

This interaction between machine parameters involves the formation of melt pools, thermal gradients and balling phenomenon. This phenomenon affects the surface quality due the randomly ejection on small solid particles distributed on the surface, involving in the material deposition by layer and then, in the internal porosity formation in the parts [6], [7]. The formation of small spherical defects is due to insufficient fusion with the previous layer and the surface tension generated during the process [3]. Then, the balling effect impairs the properties of the manufactured components in terms of surface quality and internal porosity, which reduces the mechanical properties and increases the risk of the roller blockage during the manufacturing process [6].

In this paper, the influence of the amount of laser energy in the parts quality is analysed. This amount of energy can be evaluated as energy density, $\mathrm{E}_{\mathrm{v}}\left(\mathrm{J} / \mathrm{mm}^{3}\right)$, received by the powder layer as it is shown in equation (1). Where, P is laser power $(\mathrm{W}), \mathrm{v}$ is scan speed $(\mathrm{mm} / \mathrm{s}), \mathrm{s}$ is hatch spacing $(\mathrm{mm})$ and $\mathrm{L}_{\mathrm{T}}$ is layer thickness $(\mathrm{mm})$.

$$
E_{v}=\frac{P}{v \cdot s \cdot L_{T}}
$$

The laser energy influences in the correct fusion of the powder bed, and therefore, in the final surface quality of the part. As the equation (1) shows, the energy density depends on different parameters. Whether, for reasons of productivity, the values of scanning speed, spacing and layer thickness remain constant, the energy density that reaches the powder only depends on the laser power.

Therefore, it is crucial to adjust it to obtain optimal properties of the manufactured parts. Also, another influential parameter is the defocussing. This parameter, $\Delta \mathrm{Z}$ in Fig. $1 \mathrm{~b}$, allows to modify the focal length of the scanning unit of the machine, measured during the set-up of the equipment, $f_{d}$, in order to adjust it in fine form. This setting is critical for the parts quality, because it depends on the concentration of the laser light on the powder bed, size of the laser spot, and therefore, scanning strategies calculated by the slicer software.

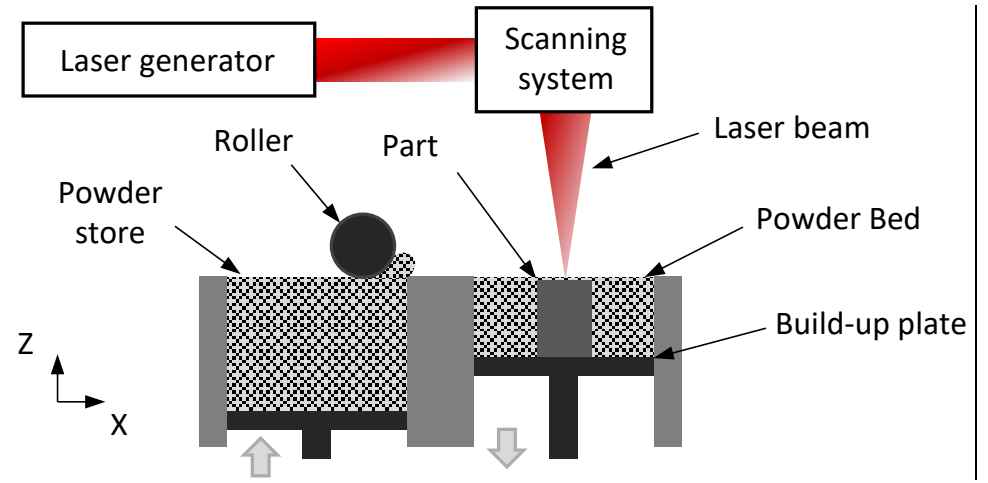

(a)

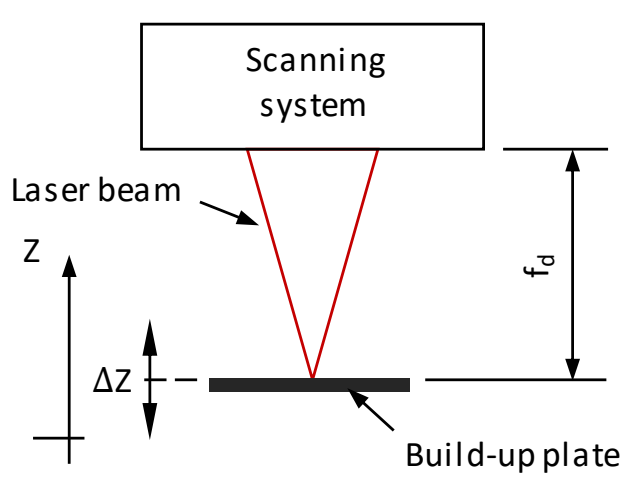

(b)

Fig. 1. Schematic work principle of SLM: (a) Scanning and powder supplier systems, (b) Focal distance $\left(\mathrm{f}_{\mathrm{d}}\right)$ and Defocussing $(\Delta \mathrm{Z})$.

Surface finish of the each layer is heterogeneous because to the additive process. That is, it depends on the orientation of each surface with respect to the machine reference system. The part grows layer by layer in $\mathrm{Z}$ direction, and the upper surface shows the strategy used by the scanning unit for the last manufactured layer (Fig. 2a). In the scanning process of each layer, usually, the layer to be melted is divided in small paths with different shapes that are melting consecutively, to reduce the action of surface tension [3], [6].

Normally these paths are hexagons or squares (chessboard style). In this work, following the indications of the machine manufacturer, the scan strategy used was hexagonal (Fig. 2). Therefore, the top surface is the more interesting to analyse the effect of the scan parameters. So that, in this work this surface was analysed. 


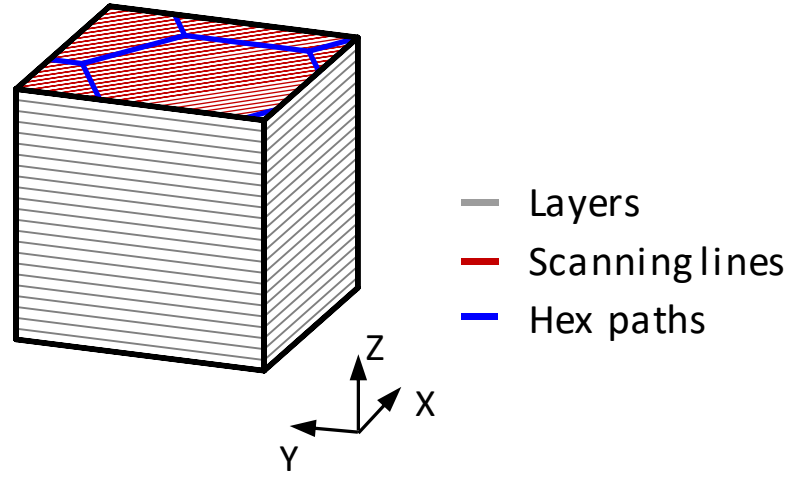

(a)

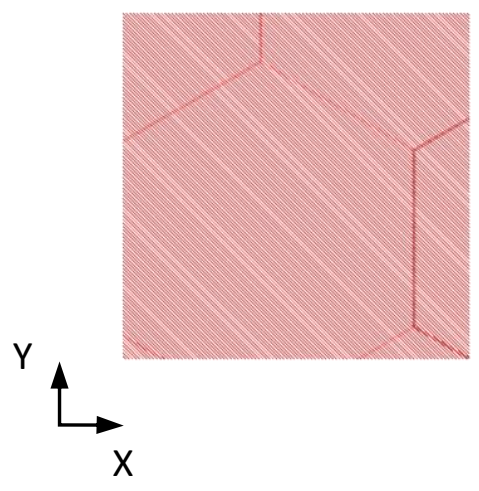

(b)

Fig. 2. Schematics of the specimens build process: (a) layers, scanning paths and hexagonal marks, (b) scanning strategy used.

Therefore, in this work, the influence of laser power and defocussing parameters on the surface quality of the parts manufactured by SLM technique is analysed. Several specimens were manufactured by varying these parameters. To assess the quality of the samples, their porosity was analysed by the Archimedes method, as it has proved one of the most reliable for these samples [8]. In addition, the upper surface of the parts was analysed both macroscopically and microscopically. For macroscopic analysis a profilometer was used to measure the Ra parameter in the $\mathrm{X}$ and $\mathrm{Y}$ directions of each specimen. For the microscopic analysis, different images were captured with a scanning electron microscope (SEM) and the balling phenomenon was analysed using a measuring software.

\section{Equipment and Methodology}

In this work a SLM Metal 3Dsystems ProX 100 machine was used, Fig. 3. Its main features are shown in Table 1.

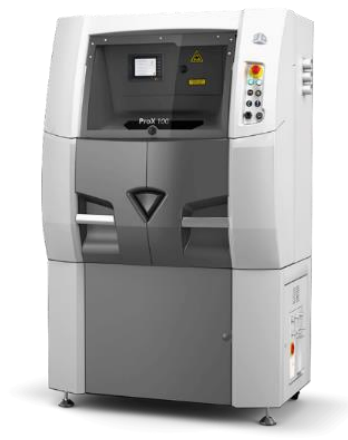

Fig. 3. ProX 100 machine.

\begin{tabular}{|l|c|c|}
\hline Property & Units & Value \\
\hline Laser max Power & $\mathrm{W}$ & 50 \\
\hline Laser Type & - & Fiber Laser \\
\hline Laser Wavelength & $\mathrm{nm}$ & 1070 \\
\hline Min Layer Thickness & $\mu \mathrm{m}$ & 10 \\
\hline Preset Layer Thickness & $\mu \mathrm{m}$ & 30 \\
\hline Repeatability X,Y,Z & $\mu \mathrm{m}$ & $20,20,20$ \\
\hline Typical Accuracy $(\mathrm{min})$ & $\%$ & $0.1-0.2(50 \mu \mathrm{m})$ \\
\hline
\end{tabular}

Table 1. Main features of the ProX 100 [9].

The material used in this research was the 17-4 PH Stainless Steel, supplied by the machine manufacturer [10]. Its composition is shown in Table 2. This material has an outstanding combination of high strength and good corrosion resistance, apart from have excellent mechanical properties at elevated temperatures, up to $300^{\circ} \mathrm{C}$, high hardness and good thermal properties [10]. The parts build with this material has a yield strength of $620 \pm 30 \mathrm{MPa}$ in as-built condition, being able to reach up to $1100 \pm 50 \mathrm{MPa}$, after a proper heat treatment [10]. Nitrogen, obtained from a generator connected to the machine, was used as inert gas during the manufacturing process.

\begin{tabular}{|c|c|}
\hline Element & \% of weight \\
\hline $\mathrm{Fe}$ & Balance \\
\hline $\mathrm{Cr}$ & $15-17.5$ \\
\hline $\mathrm{Ni}$ & $3-5$ \\
\hline $\mathrm{Cu}$ & $3-5$ \\
\hline $\mathrm{Si}$ & $<1.0$ \\
\hline $\mathrm{Mn}$ & $<1.0$ \\
\hline $\mathrm{Nb}$ & $0.15-0.45$ \\
\hline
\end{tabular}

Table 2. 17-4PH powder properties. 
In order to analyse the effect of the laser power, $\mathrm{P}$, and the defocussing parameter, $\mathrm{D}$, in the surface finishing of the parts built by the ProX 100, several $10 \mathrm{~mm}$ sideways cubic specimens were manufactured, modifying these parameters. Before manufacture the specimens, a preliminary test was carried out due to found a valid range of these parameters. In this test, some cubes were manufactured using different setup of the analysed parameters (Fig. 4). The scan style used in this case was Hexagonal. This scan style divides each layer to be manufactured in hexagonal patches, which are inscribed in a circles of $5000 \mu \mathrm{m}$ of radius and have an overlap of $50 \mu \mathrm{m}$ between neighbours. Both this scan style, the scan speed, $140 \mathrm{~mm} / \mathrm{s}$, and the layer thickness, $30 \mu \mathrm{m}$, were kept constant during the all work.
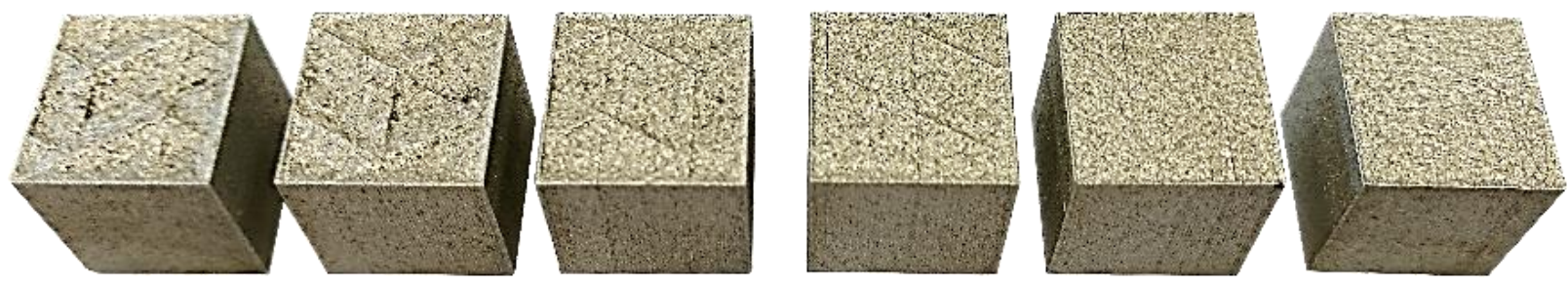

Fig. 4. Some of the preliminary test specimens.

In this preliminary test, the variation of the laser power allowed to set an initial value of power, $38.5 \mathrm{~W}$ in this case. While the variation of defocusing allowed to base the acceptable variation range of this parameter respect to the focal distance measured during the initial setup of the machine (Fig. 1b), $1 \mathrm{~mm}$ in this case. Thanks to this, the levels and values of the analysed parameters could be established: $38 \mathrm{~W}, 38.5 \mathrm{~W}, 39 \mathrm{~W}$ of laser power and $+1 \mathrm{~mm}, 0 \mathrm{~mm},-1 \mathrm{~mm}$ of defocusing. These SLM manufacturing parameters were set in the slicer DMP ProX Manufacturing software, which is specific for this type of machine. In this software, the cubes were also located and orientated in the build-up plate of the machine in order to facilitate the manufacturing process. That is, to ensure the good compaction of the powder by the roller, which moves along the $\mathrm{X}$ axis (Fig. 5). Once the specimens were built, they were separated from the build-up plate by means of wire EDM.

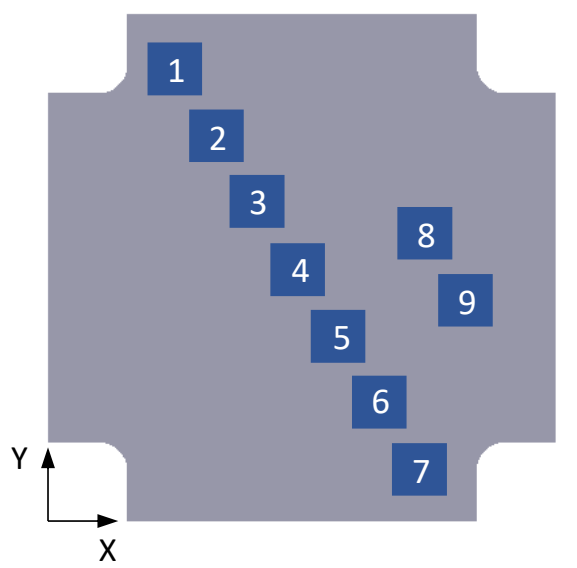

(a)

\begin{tabular}{|c|c|c|}
\hline$\#$ & $\mathrm{P}(\mathrm{W})$ & $\mathrm{D}(\mathrm{mm})$ \\
\hline 1 & 38.0 & \multirow{2}{*}{0} \\
\cline { 1 - 2 } 2 & 38.5 & \multirow{2}{*}{0} \\
\cline { 1 - 2 } 3 & 39.0 & \\
\cline { 1 - 2 } 4 & 38.0 & \multirow{2}{*}{+1} \\
\cline { 1 - 2 } 5 & 38.5 & \multirow{2}{*}{+1} \\
\cline { 1 - 2 } 6 & 39.0 & \\
\cline { 1 - 2 } 7 & 38.0 & \multirow{2}{*}{-1} \\
\cline { 1 - 2 } 8 & 38.5 & \\
\cline { 1 - 2 } 9 & 39.0 & \\
\hline
\end{tabular}

(b)

Fig. 5. Specimens: (a) distribution on the manufacturing plate, (b) Power and Defocussing values.

The porosity of the specimens was measured using Archimedes' principle. For that, it was necessary to know their reachable density after the SLM process, $7760 \mathrm{~kg} / \mathrm{m}^{3}$ [11], and their dimensions, which were obtained by means a centesimal micrometre (the specimens were supposed perfectly cubic).

\subsection{Superficial analysis}

In the case of the surface quality evaluation of the top surface of the specimens, SEM images was used. These images were captured at two magnification levels:

- The lower magnification (x33) allowed to get an overview of the surface, in order to detect critical defects if were exist. In the Fig. 6, Mosaics of the top surface of two specimens are shown. As can be noticed, there aren't critical defects in the surfaces. Nevertheless, in some specimens open porosity near to the boundary of the top surface was detect (Fig. 6b). 


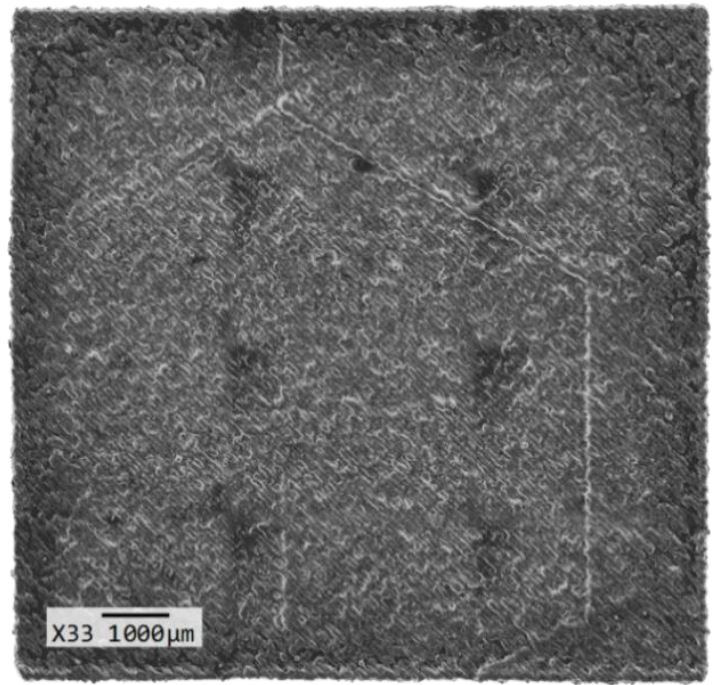

(a)

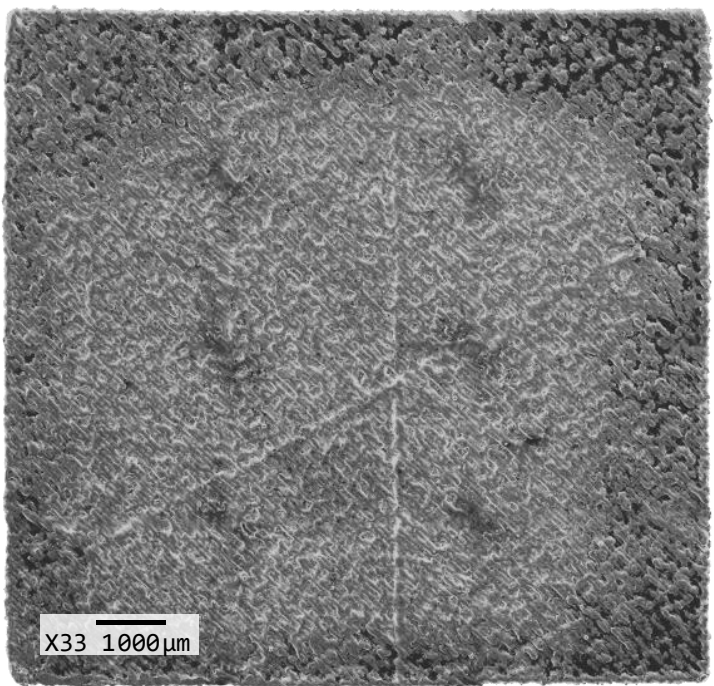

(b)

Fig. 6. Examples of specimens mosaics: (a) $38.5 \mathrm{~W} 0 \mathrm{~mm}$, (b) $39 \mathrm{~W}+1 \mathrm{~mm}$.

- The higher magnification (x150) allowed to perform a thorough analysis of the surface quality. So that, the usual balling phenomenon could be evaluated related to the setup of the analysed parameters. The balling particles were classified in three different types according to their diameter using the image processing program ImageJ [12]:

- Type A: greater than $20 \mu \mathrm{m}$.

- Type B: between 10 and $20 \mu \mathrm{m}$. The size of these particles are similar to the particles of the metallic powder used (also analysed by means of SEM).

- Type C: lower than $10 \mu \mathrm{m}$. This particles usually appear concentrated in different positions of the surface.

Five images of each specimen were analysed. These images were captured in random positions of each specimen top surface. All the particles that appeared in these images were analysed and classified in the appropriate type. In the case of the Type A and B particles, both diameter and number of particles were evaluated. These type of particles were supposed circular. On the other hand, in the case of balling type $\mathrm{C}$ particles, due to their small diameter and the fact that this type of particles usually appear concentrated, they weren't measured individually. On the contrary, the area occupied by this concentrations was evaluated. Fig. 7 shows examples of the three types of balling analysed.

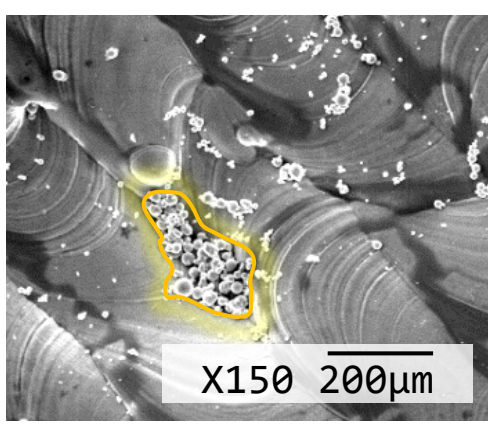

(a)

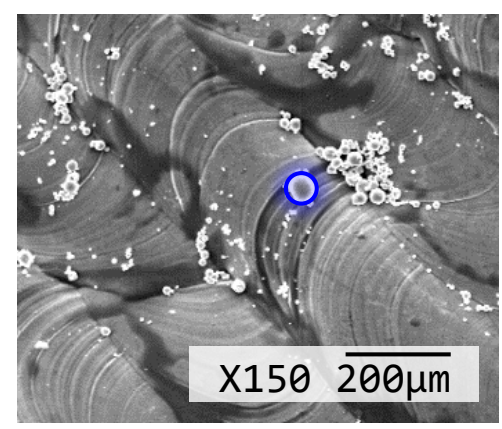

(b)

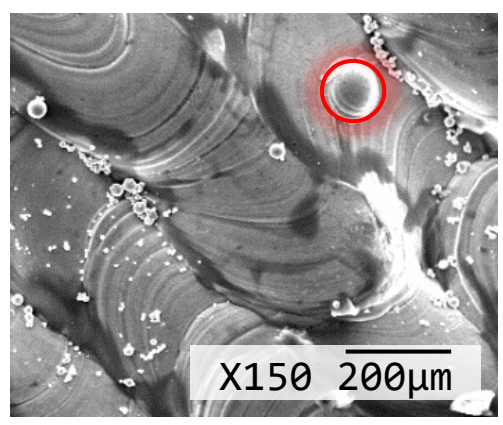

(c)

Fig. 7. Examples of different types of balling analysed: (a) Type A, (b) Type B, (c) Type C.

Finally, the roughness finishing of the top surface of the specimens were measured by means of a Mitutoyo contact profilometer Surftest SJ-500. In order to get a reliable evaluation of the roughness, three profiles in both X and Y direction were measured (Fig. 5a). This profiles were distributed along these two directions. Then, the measurements were averaged for each case.

\section{Results and discussion}

Fig. 8 shows the results obtained using the Archimedes method for the total porosity of the specimens. The total porosity (open and closed) is in the range of 3.36 to $4.02 \%$. 
The combination of Power $38 \mathrm{~W}$ and Defocussing $-1 \mathrm{~mm}$ shows the lowest porosity values, while the combination of $38 \mathrm{~W},+1 \mathrm{~mm}$ the highest. Although with the increase of $\mathrm{P}$ and D parameters a slight tendency is observed in the increase of porosity, it is not so significant.

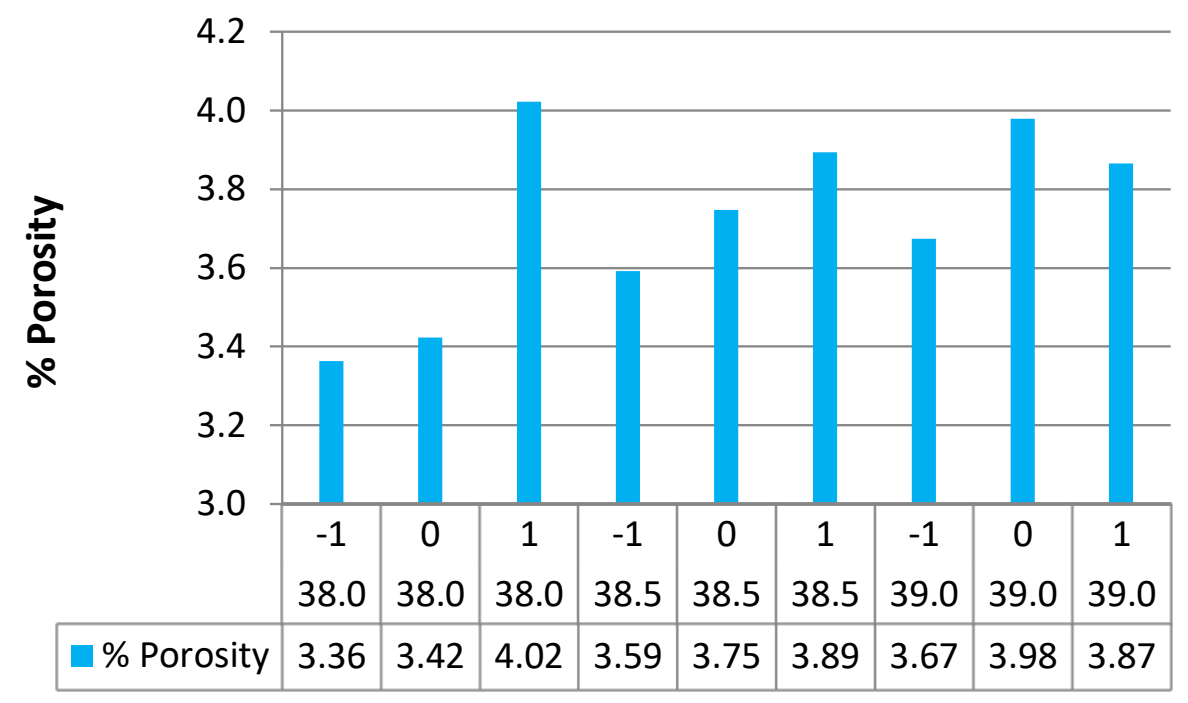

\section{Setup parameters: $D(\mathrm{~mm})$ and $P(W)$}

Fig. 8. Porosity percentage of the specimens.

Regarding balling, Fig. 9a shows the number of particles (type A and B), and Fig. 9b shows the average particle size:

- For both types (A and B), the number of particles increases with the increase of D parameter. Also, there are differences between the powers used, obtaining a similar number of particles of both types for the powers of 38.0 and $38.5 \mathrm{~W}$. With a power of $39.0 \mathrm{~W}$, a lower number of particles type A was obtained, but greater in type B.

- No clear trend is observed regarding the average particle diameters as a function of P and D parameters. Similar values were obtained in all cases for the diameters of both types of particles.

These results indicate that the $\mathrm{P}$ and $\mathrm{D}$ parameters aren't determinant regarding the size of the balling particles but they are determinant regarding the number of them.

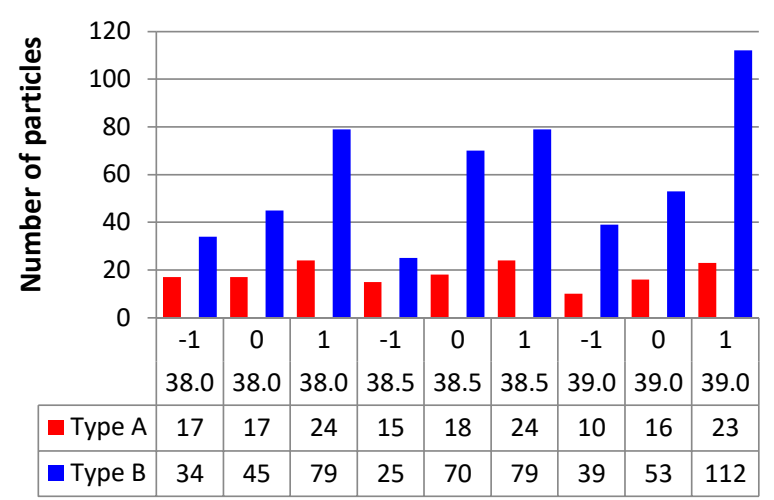

Setup parameters: $D(\mathrm{~mm})$ and $P(W)$

(a)

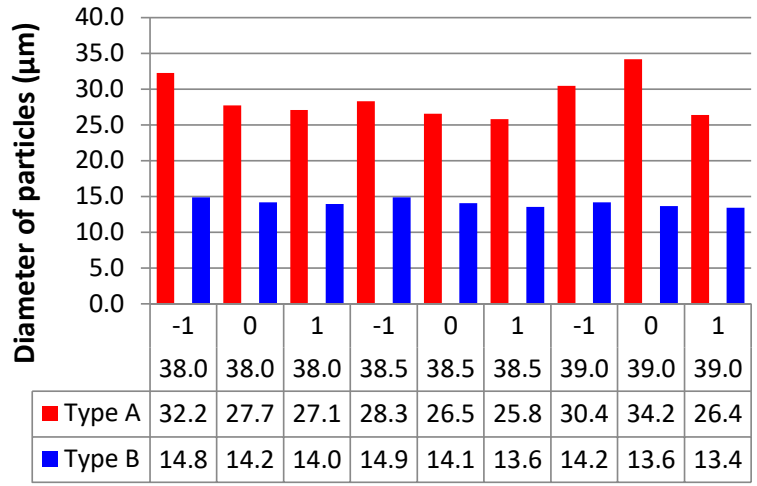

Setup parameters: $D(\mathrm{~mm})$ and $P(W)$

(b)

Fig. 9. Results of balling type A and B analysis.

Regarding the size of the area taken by type $\mathrm{C}$ balling, Fig. 10 shows no clear relationship with $\mathrm{D}$ and $\mathrm{P}$ parameters. This could indicate that the amount of this type of particles depends more on other factors, such as the open porosity present in the surface. Porosity in which this type of particles tend to agglomerate. 


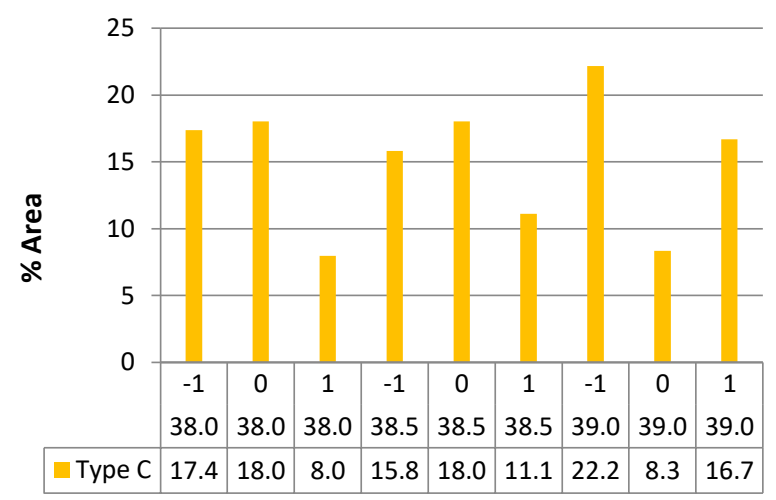

Setup parameters: $D(\mathrm{~mm})$ and $P(W)$

Fig. 10. Results of balling type C analysis.

Finally, Fig. 11 shows the results obtained in the measurement of roughness (Ra values) for each configuration of $\mathrm{P}$ and D parameters. Although the roughness obtained for the powers of $38.5 \mathrm{~W}$ and $39.0 \mathrm{~W}$ is slightly lower than that obtained for the power of $38.0 \mathrm{~W}$, the roughness obtained for all cases is similar. In addition, except for the combination of $38.5 \mathrm{~W}$ and $+1 \mathrm{~mm}$, the roughness obtained in both directions $\mathrm{X}$ and $\mathrm{Y}$, it's practically equivalent.

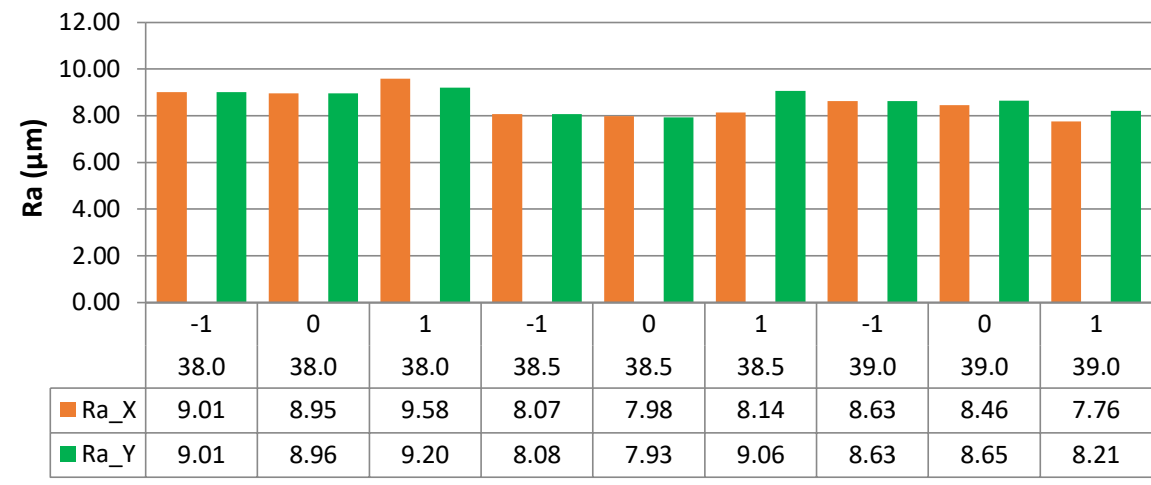

Setup parameters: $D(\mathrm{~mm})$ and $P(W)$

Fig. 11. Surfaces roughness measured.

\section{Conclusions}

In this work, the influence of laser power and defocussing parameters of the SLM process in the surface quality of the parts had been analysed. For that, after a preliminary test carried out in order to found a valid range of the studied parameters, several specimens variyin that parameters were built. Once the specimens were built, their porosity was analyse using the Archimedes method. Then, the quality of the top surface of the specimens was analysed both macroscopically and microscopically. These analysis were carried out by means a contact profilometer and a SEM, respectively. In the macroscopic analysis the Ra parameter of each specimen was analysed related to the orientation of the coordinate reference system of the machine. In the microscopic analysis, the balling phenomenon was analysed, classifying the different particles found in different types related to the size of them and the size of the original powder.

Total porosity of the specimens increases with the increase of power and defocussing parameters. The balling showed a relationship with the defocussing parameter, regarding the number of particles, but not in the case of their size. This is relevant in particles with bigger size that the average particle size of the original metallic powder. Smaller particles of balling didn't show a clear trend, so it seems that other factors such as the appearance of open porosity on the surface may have greater influence than the parameters studied.

Roughness results show no clear advantage of one combination of the studied parameters in front of the other combinations, indicating that the balling effect observed and the total porosity don't have important influence in this indicator. Moreover, no significant differences were observed in the roughness in the two directions X and Y studied, which indicates isotropy of this characteristic of the surface.

Based on the results obtained in this work, it is proposed to analyse the influence of the studied parameters in the surface quality of the rest of the faces of the specimens, in order to optimize the surface quality of the specimens in general. Moreover, it is proposed to analyse the possible relationship of the appearance of the small balling particles related to the appearance of open porosity in the surface of the specimens, in order to reduce them. 


\section{Acknowledgments}

We gratefully acknowledge the financial support provided by the Junta de Castilla y León and FEDER (project LE027P17) and by the Spanish Ministry of Economy, Industry and Competitiveness (project DPI2017-89840-R).

\section{References}

[1] Strano, G.; Hao, L.; Everson, R.M. \& Evans, K.E. (2013). Surface roughness analysis, modelling and prediction in selective laser melting, J. Mater. Process. Technol., Vol. 213, No. 4, 2013, pp. 589-597, ISSN 0924-0136, DOI 10.1016/j.jmatprotec.2012.11.011.

[2] Spierings, A.; Wegener, K. \& Levy, G. (2014). Designing material properties locally with additive manufacturing technology SLM, Proceedings of 23rd Annual International Solid Freeform Fabrication Symposium - An Additive Manufacturing Conference, SFF 2012, Zurich, pp. 447-455, ISSN 8610828378018, DOI 10.3929/ethz-a010335595.

[3] Yap, C. Y.; Chua, C. K.; Dong, Z. L.; Liu, Z. H.; Zhang, D. Q.; Loh, L. E. \& Sing, S. L. (2015). Review of selective laser melting: Materials and applications, Applied physics reviews, Vol. 2, No. 4, 2015, pp. 041101, ISSN 19319401, DOI 10.1063/1.4935926.

[4] Alrbaey, K.; Wimpenny, D.; Tosi, R.; Manning, W. \& Moroz, A. (2014). On optimization of surface roughness of selective laser melted stainless steel parts: a statistical study, Journal of Materials Engineering and Performance, Vol. 23, No. 6, 2014, pp. 2139-2148, ISSN 15441024, DOI 10.1007/s11665-014-0993-9.

[5] Hanzl, P.; Zetek, M.; Bakša, T. \& Kroupa, T. (2015). The influence of processing parameters on the mechanical properties of SLM Parts, Procedia Engineering, 25th DAAAM International Symposium on Intelligent Manufacturing and Automation, Czech Republic, Vol. 100, January 2015, pp. 1405-1413, ISSN 18777058, DOI 10.1016/j.proeng.2015.01.510.

[6] Li, R.; Liu, J.; Shi, Y.; Wang, L. \& Jiang, W. (2012). Balling behavior of stainless steel and nickel powder during selective laser melting process, Int. J. Adv. Manuf Technol, Vol. 59, No. 9-12, 2012, pp. 1025-1035, ISSN 02683768, DOI 10.1007/s00170-011-3566-1.

[7] Kruth, J.P.; Froyen, L.; Van Vaerenbergh, J.; Mercelis, P.; Rombouts, M. \& Lauwers, B. (2004). Selective laser melting of iron-based powder, Journal of Materials Processing Technology, Vol. 149, No. 1-3, 2004, pp. 616-622, ISSN 09240136, DOI 10.1016/j.jmatprotec.2003.11.051.

[8] Spierings, A. B.; Schneider, M. \& Eggenberger, R. (2011). Comparison of density measurement techniques for additive manufactured metallic parts, Rapid Prototyping Journal, Vol. 17, No. 5, 2011, pp. 380-386, ISSN 13552546, DOI 10.1108/13552541111156504.

[9] 3DSystems (2017). Direct Metal Printers Spec Sheet.

[10] 3DSystems (2017). LaserForm 17-4PH (B).

[11] 3DSystems (2014), Safety DataSheet PS4542A 17-4 PH Stainless Steel, Rev. 2014.

[12] https://imagej.net/ImageJ. ImageJ community website, Accessed on: 2018-06-22. 